ARTICLE

https://doi.org/10.1038/s41467-019-11035-w

\title{
Divergent changes in the elevational gradient of vegetation activities over the last 30 years
}

\author{
Mengdi Gao', Shilong Piao (1) ${ }^{1,2}$, Anping Chen (10 ${ }^{3}$, Hui Yang ${ }^{1}$, Qiang Liu (1) 1, Yongshuo H. Fu ${ }^{4,5}$ \& \\ Ivan A. Janssens (1) ${ }^{5}$
}

The reported progressive change of vegetation activity along elevational gradients has important aesthetic and conservation values. With climate change, cooler locations are suggested to warm faster than warmer ones, raising concerns of a more homogenized landscape along the elevation. Here, we use global satellite data to investigate the spatiotemporal dynamics of the elevational gradient $(E G)$ in vegetation greenness (NDVI $\max _{3}$ ), spring (SOS) and autumn phenology (EOS) during 1982-2015. Although we find clear geographical patterns of the EG in NDVI $I_{\max 3}$ and SOS, there are no prevalent trends of vegetation homogenization or phenology synchronization along elevational gradients. Possible mechanisms, including spatially heterogeneous temperature lapse rate changes, different vegetation sensitivities to climate change, and human disturbances, may play diverse roles across different regions. Our finding of mixed EG trends and no general rules controlling EG dynamics poses challenges for mitigating possible adverse impacts of climate change on mountainous biological diversity and ecosystem services.

\footnotetext{
${ }^{1}$ Sino- French Institute for Earth System Science, College of Urban and Environmental Sciences, Peking University, 100871 Beijing, China. ${ }^{2}$ Key Laboratory of Alpine Ecology, Institute of Tibetan Plateau Research, Center for Excellence in Tibetan Earth Science, Chinese Academy of Sciences, 100085 Beijing, China. ${ }^{3}$ Department of Biology, Colorado State University, Fort Collins, CO 80523, USA. ${ }^{4}$ College of Water Sciences, Beijing Normal University, Beijing, China.

${ }^{5}$ Department of Biology, University of Antwerp, Universiteitsplein 1, B-2610 Wilrijk, Belgium. Correspondence and requests for materials should be addressed to S.P. (email: slpiao@pku.edu.cn)
} 
$\mathrm{V}$ egetation activity often displays a clear elevational pattern ${ }^{1,2}$. Such an elevational pattern of vegetation activity can refer to vegetation phenology. For example, the dates of spring leaf unfolding and autumn leaf senescence have been observed to progressively change from low to high elevations for many regions ${ }^{3,4}$. It can also be related to vegetation growth and greenness ${ }^{5}$. At many places, vegetation growth and greenness have been found to change progressively with elevation as a result of differences in climate or in nutrient availability ${ }^{6}$ (relative to an optimum). Spatially, progressively changing vegetation activity along elevational gradients have been reported for many temperate and boreal regions ${ }^{7}$, with some cases also observed for the tropics 8,9 . This progressive vegetation activity change creates fascinating natural beauties that have been subjects of admirations in poems and proses for many generations. For instance, the great Chinese poet Bai Juyi once famously wrote, "In the plains past April, flowers have all but gone; In the hills at the temple, 'tis the time for the peach blossoms to bloom". It also helps maintain a diverse landscape of ecosystem structures and functions, particularly in mountainous areas that harbor the highest terrestrial biodiversity and provide critical ecosystem services to society.

Elevation-dependent temperature differences are often regarded as the main cause for the observed differences in vegetation activity along elevational gradients 5 . With climate change, however, there is an increasing concern that this elevationally progressive pattern of vegetation activity may be altered ${ }^{10-12}$. Specifically, the warming rate is often faster at higher than at lower elevations, leading to a trend of temperature homogeniza$\operatorname{tion}^{13}$. This temperature homogenization has also been observed along latitudinal gradients, where it is believed to contributed to species and ecosystem homogenization ${ }^{14}$. The question thus arises whether, analogous to latitudinal temperature and ecosystem homogenization, elevation-dependent warming would also lead to more homogenized or synchronized vegetation activity? The elevational pattern of vegetation activity changes over the past decades under the reported significant climate change has to date not been studied. Because a more homogenized or synchronized vegetation pattern may reduce both the aesthetic aspects and functional diversities, addressing these questions is important for understanding and predicting vegetation activity and its ecosystem functioning under climate change.

Here, we use satellite-derived vegetation activity data to investigate how the relationship between vegetation activity and elevation may have changed over the past three decades. We consider three vegetation activity indicators that are derived from the Advanced Very High Resolution Radiometer (AVHRR) GIMMS NDVI ${ }_{3 \mathrm{~g}}$ dataset over 1982-2015 at the spatial resolution of $8 \mathrm{~km} \times 8 \mathrm{~km}$ to represent vegetation activity strength and phenology: the maximum three-monthly normalized difference vegetation index $\left(\mathrm{NDVI}_{\max 3}\right)$, the start date of the growing season (SOS), and the end date of the growing season (EOS). These three vegetation activity indices provide key information for understanding vegetation growth, carbon cycles, and vegetation phenology, and have been found to show clear elevational patterns in many regions $s^{15,16}$. Here the relationship between vegetation activity and elevation is quantified as an elevational gradient (EG), which is defined as the average change of a vegetation activity index per $100 \mathrm{~m}$ increase in elevation. For each $8 \mathrm{~km} \times 8$ $\mathrm{km}$ grid cell, we estimate multi-year EG of vegetation activities by regressing the multi-year averaged vegetation activity indicators against its elevation in a $9 \times 9$ moving window centered at the focused grid cell (see Methods). Similarly, we also estimate EG for each year with annual vegetation activity data, and then derive the temporal EG trend using least squares linear regressions between annual EG and the year (see Methods). Note in this study, we use the average value from four different phenology derivative algorithms as the estimated SOS or EOS (see Methods). To test the robustness of the results, we also use other moving window sizes, i.e., $5 \times 5,7 \times 7,11 \times 11,13 \times 13$ (see Methods). The aim of this study is three-fold: (1) to investigate the EG of the above three vegetation activity indicators during 1982-2015 and their spatial patterns; (2) to test if the temporal evolution of these elevational gradients follows a hypothetic trend of increased homogenization or synchronization; and (3) to identify possible mechanisms underlying the observed spatio-temporal dynamics of vegetation activity EG.

\section{Results}

Multi-year averaged EG of vegetation activities. We first explored the spatial patterns of the multi-year averaged EG values for each of the three vegetation activity indices during 1982-2015 (Fig. 1). The results showed highly heterogeneous, rather than consistent patterns of EG values across the global land surface for all three vegetation activity indices. The $\mathrm{EG}$ of $\mathrm{NDVI}_{\max 3}$ $\left(\mathrm{EG}_{\text {ndvimax }}\right)$ was negative (decreased vegetation greenness at higher elevations) in about $38 \%$ of the study area, mostly in cold regions including the Tibetan Plateau and the Artic regions (Fig. 1a). By contrast, it was positive (increased vegetation greenness at higher elevations) in the tropics and in most temperate regions, such as south-eastern America, Central Europe, and Eastern China (Fig. 1a). Furthermore, $E_{\text {ndvimax }}$ calculated with other moving window sizes also showed similar patterns (Supplementary Fig. 1), proving the robustness of the spatial pattern of $\mathrm{EG}_{\text {ndvimax }}$ shown in Fig. 1a.

The highly varied $\mathrm{EG}_{\text {ndvimax }}$ pattern may be caused by regional differences in the dominant mechanisms governing vegetation greenness. In cold regions, vegetation growth is mostly limited by low temperature ${ }^{17}$, and decreased vegetation greenness with increasing elevation (negative $E G_{\text {ndvimax }}$, Fig. 1a) is therefore probably related to the cooler temperature at higher elevations (negative EG in temperature $\left(\mathrm{EG}_{\mathrm{tem}}\right)$, Fig. $2 \mathrm{a}$ and Supplementary Fig. 2a). In the tropics, where vegetation often grows near its thermal optimum, temperature may not be such a dominant limiting factor for vegetation greenness ${ }^{18,19}$. Instead, in the tropics the lower temperatures at increasing elevation may actually reduce evapotranspiration demand and respiratory carbon losses, resulting in enhanced vegetation growth and greenness at higher elevations. Furthermore, in many temperate regions, the increase of precipitation (Fig. $2 \mathrm{~b}$ and Supplementary Fig. 2b) may have contributed to the observed positive $\mathrm{EG}_{\text {ndvimax }}$ (Fig. 1a). Numerous field studies ${ }^{20,21}$ have suggested that increasing precipitation along the elevation facilitated vegetation growth at higher elevations. The positive $\mathrm{EG}_{\text {ndvimax }}$ may also be partly attributed to the reduction of human disturbances at higher elevations (Fig. 2c, d). For instance, the impact of reduced human activities at higher elevations, including reduced thinning intensity and less pollution ${ }^{22}$, can be particularly important for determining the sign of $\mathrm{EG}_{\text {ndvimax }}$ in densely populated regions like Eastern North America, Europe, Eastern and Southern China.

The spatial distribution of the elevation gradient of SOS $\left(\mathrm{EG}_{\mathrm{SOS}}\right)$ was also very heterogeneous, although positive $\mathrm{EG}_{\mathrm{sOS}}$ (later start of growing season at higher elevations) dominated in most of the study area (about $68 \%$, Fig. 1b). The largest $\mathrm{EG}_{\mathrm{SOS}}$ appeared in Northern Europe and in south-eastern America, where SOS dates were often delayed by more than 5 days when climbing up every $100 \mathrm{~m}$ (Fig. 1b). By contrast, negative $\mathrm{EG}_{\mathrm{SO}}$ values were found in northeast North America and central Europe (Fig. 1b). In addition, analyses with each of the four methods in deriving SOS from satellite imagery (Supplementary Fig. 3), rather than using the four-method averaged value, all 


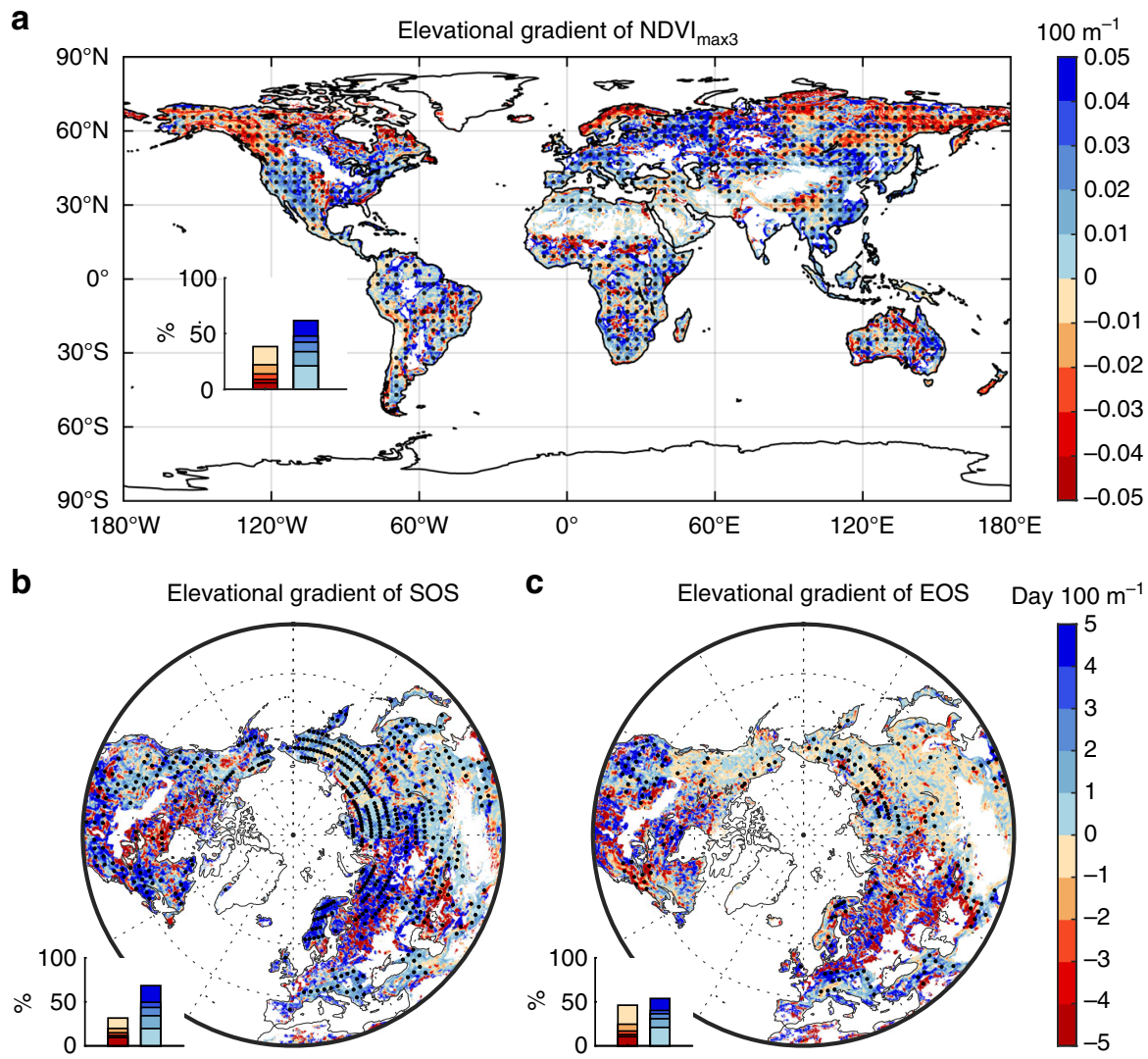

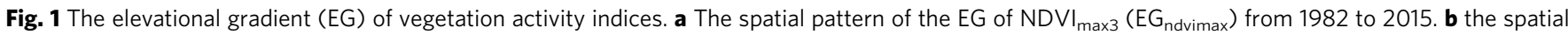
pattern of the EG of SOS ( $E_{S O S}$ ) from 1982-2011 over the Northern Hemisphere (north of $30^{\circ} \mathrm{N}$ ). c The spatial pattern of the EG of EOS (EGEOS) from 1982 to 2011 over the Northern Hemisphere. A frequency distribution of the EG values is shown in the inset at the bottom-left for each panel. Regions marked with dots have statistically significant $(p<0.05$ with the $F$-test) EG values

showed similar spatial patterns in $\mathrm{EG}_{\mathrm{SOS}}$ as those shown in Fig. 1b. The corroborated results with different methods further confirmed the robustness of our finding about the spatial distribution of $\mathrm{EG}_{\mathrm{SO}}$ signs.

The positive $\mathrm{EG}_{\mathrm{SOS}}$ over most regions is very likely attributable to the decreased temperature with elevation ${ }^{3}$, i.e. negative $\mathrm{EG}_{\mathrm{tem}}$. As shown in Supplementary Fig. $4 \mathrm{a}$ and $4 \mathrm{~b}$, spring temperature decreases with increasing elevation in most regions. In northeast North America, however, both WorldClim ${ }^{23}$ and ERA Interim temperature datasets ${ }^{24}$ show increasing spring temperature with elevation (positive spring $\mathrm{EG}_{\text {tem }}$ ), which explains the observed negative $\mathrm{EG}_{\mathrm{SO}}$ there.

Unlike $\mathrm{EG}_{\mathrm{SOS}}$, the $\mathrm{EG}$ of $\mathrm{EOS}\left(\mathrm{EG}_{\mathrm{EOS}}\right)$ showed a more fragmented spatial pattern (Fig. 1c). Positive EG $E_{\mathrm{EOS}}$ values (later autumn senescence at higher elevations) were found in southeast Europe and western North America, while negative ones (earlier autumn senescence at higher elevations) were found in high latitude regions and eastern Asia. Also in contrast to $\mathrm{EG}_{\mathrm{SOS}}$, the spatial patterns of $\mathrm{EG}_{\mathrm{EO}}$ derived with different methods did not always corroborate (Supplementary Fig. 5). In particular, the pattern derived with the piecewise logistic method was significantly different from that obtained with the other three methods (i.e., HANTS, polyfit, and double logistic, see Methods). Further analyses showed that autumn NDVI increased with elevation in most regions (Supplementary Fig. 6), and that the spatial pattern of the elevational gradient of autumn NDVI $\left(E G_{n d v i a u}\right)$ was consistent with that of $E_{E O S}$ based on the algorithms HANTS, polyfit, and double logistic, being mostly $(56 \%)$ positive across the study area. The evidence from $\mathrm{EG}_{\text {ndviau }}$ therefore appears to support the elevational EOS changes derived with the algorithms of HANTS, polyfit, and double logistic.

Like spring temperature, autumn $\mathrm{EG}_{\text {tem }}$ was also mostly negative (Supplementary Fig. 7a, c), inconsistent with the highly mixed spatial distribution of $\mathrm{EG}_{\mathrm{EOS}}$. This spatial mismatch between autumn $\mathrm{EG}_{\text {tem }}$ and $\mathrm{EG}_{\mathrm{EOS}}$ suggests that autumn temperature may not be the main environmental factor controlling autumn phenology. It has been suggested that radiation, precipitation, winter warming and even spring phenology ${ }^{25-27}$ can all impact autumn phenology. We find that autumn precipitation amplifies with elevation in most regions (Supplementary Fig. 7b, d), which may contribute to the postponed autumn phenology and enhanced autumn NDVI at higher elevations in some regions. Furthermore, the temperature sensitivity of autumn phenology is smaller than that of spring phenology ${ }^{17}$, which may also help explain the more fragmented spatial pattern of $\mathrm{EG}_{\mathrm{EOS}}$. Nonetheless, so far our knowledge on the major mechanisms shaping the spatio-temporal pattern of autumn phenology remains very limited ${ }^{28-30}$

Temporal dynamics of EG of vegetation activities. Next, we examined the temporal trends of the annual EG of vegetation activities from 1982 to 2015 . To facilitate hypothesis testing, we calculated for each grid cell both the multi-year averaged EG sign and the temporal change in EG. Along the elevational gradient, the multi-year averaged EG sign can either (1) indicate increasing vegetation activity (positive $\mathrm{EG}_{\text {ndvimax }}$, negative $\mathrm{EG}_{\mathrm{SOS}}$, and positive $\mathrm{EG}_{\mathrm{EOS}}$ ) or (2) suggest decreasing vegetation activity (negative $\mathrm{EG}_{\text {ndvimax }}$, positive $\mathrm{EG}_{\mathrm{SOS}}$, and negative $\mathrm{EG}_{\mathrm{EOS}}$ ). Over 

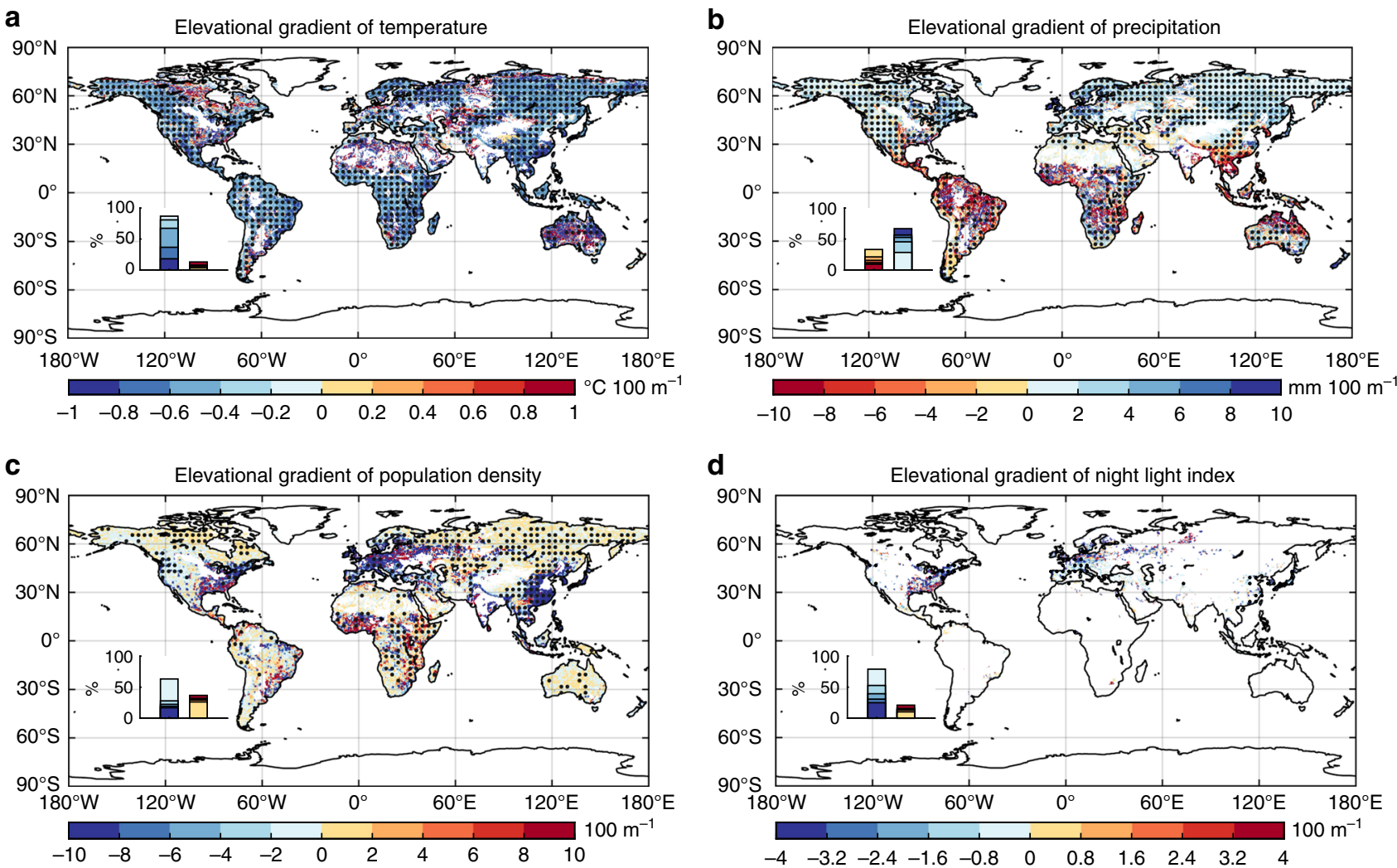

Fig. 2 The elevational gradient (EG) of climate and human activity variables. a The spatial pattern of the $E G$ of mean annual temperature (EG tem). $\mathbf{b}$ The spatial pattern of the $E G$ of total precipitation $\left(E G_{p r e}\right)$. $\mathbf{c}$ The spatial pattern of the EG of population density $\left(E G_{p d}\right)$. $\mathbf{d}$ The spatial pattern of the EG of night light index $\left(E G_{N L I}\right)$. A frequency distribution of the $E G$ values is shown in the inset at the bottom-left for each panel. Regions marked with dots have statistically significant ( $p<0.05$ with the $F$-test) EG values

time, the EG sign can be either (A) amplified or (B) reduced. The combined changes in EG along the elevational gradient and over time are illuminated in Fig. 3. Here (1A) and (2A) indicate increased elevational vegetation dissimilarity; while (1B) and (2B) imply reduced vegetation dissimilarity, i.e. increased elevational vegetation homogenization/synchronization.

For vegetation greenness $\left(\mathrm{EG}_{\text {ndvimax }}\right)$, we observed that about $48 \%$ of the study area falls into categories (1A) and (2A) (Fig. 4a). Spatially, the temporal trend of $\mathrm{EG}_{\text {ndvimax }}$ was very fragmented (Fig. 4a). Category (1A) was mainly found in southeast Europe, Eastern European highlands, southern Africa and the Rocky Mountains. By contrast, category (1B) was mostly observed in western India, Southeast China, eastern Australia, and western Europe. Category (2A) mainly occurred in the Siberian boreal region; while category (2B) was mainly found in Alaska and the Yukon region. Overall, this result of fragmented spatial distribution of the four categories of $\mathrm{EG}_{\text {ndvimax }}$ trends suggests that the elevational difference in vegetation greenness is not prevalently reduced and that the prediction of increased elevational homogenization of vegetation greenness is not supported.

The geographic distributions of the temporal trends in elevational temperature and precipitation gradients $\left(\mathrm{EG}_{\mathrm{tem}}\right.$ or the elevational lapse rate of temperature, and $\mathrm{EG}_{\text {pre, }}$ respectively) were also mixed (Supplementary Fig. 8a, b). However, the spatial pattern of the sign of the $\mathrm{EG}_{\text {tem }}$ or $\mathrm{EG}_{\text {pre }}$ trends did not well match the pattern of the $\mathrm{EG}_{\text {ndvimax }}$ trends (comparing Fig. 4a with Supplementary Fig. 8a, b), indicating that changes in $\mathrm{EG}_{\mathrm{tem}}$ or $\mathrm{EG}_{\text {pre }}$ may not have been the dominant reason for the observed $\mathrm{EG}_{\text {ndvimax }}$ trends at the global scale. Nonetheless, $\mathrm{EG}_{\text {tem }}$ or $\mathrm{EG}_{\text {pre }}$ changes may have explained some $\mathrm{EG}_{\text {ndvimax }}$ trends at the regional scale. For example, the reduced negative $\mathrm{EG}_{\text {ndvimax }}$ trend in western Europe may have resulted from the associated negative $\mathrm{EG}_{\text {tem }}$ trend, while the same $\mathrm{EG}_{\text {ndvimax }}$ trend in eastern Australia may be attributable to the negative $\mathrm{EG}_{\mathrm{pre}}$ trend. Human activities may also have contributed considerably to the EG trends in some specific regions (Supplementary Fig. 8c, d). Fast population growth can imply increased anthropogenic disturbances and more frequent thinning (reduced vegetation greenness). For example, in central China, faster population growth at higher elevations may be responsible for the observed $E_{\text {ndvimax }}$ decrease, while in western Europe, faster population growth at lower elevations is likely one reason leading to the increased $\mathrm{EG}_{\text {ndvimax }}$ (Supplementary Fig. 8c, d). In addition, anthropogenic activities such as afforestation may also enhance vegetation activities. For instance, substantial afforestation has been implemented in regions like eastern China since the $1980 \mathrm{~s}^{31,32}$, mainly at lower elevations (Supplementary Fig. 9). As a result, the increasing afforestation at lower elevations leads to a negative temporal trend of $\mathrm{EG}_{\text {ndvimax }}$.

We further investigated the changes of EG in spring and autumn phenology (SOS and EOS) using the same method. For both $\mathrm{EG}_{\mathrm{SO}}$ and $\mathrm{EG}_{\mathrm{EOS}}$ we found that only about half of the study area fell into categories (1B) and (2B) that represent increased elevational synchronization of spring and autumn phenology (Fig. 4b, c). Therefore, these results also did not support the concept of global warming-induced synchronization at the global scale.

Interestingly, although most of the spatial pattern of $\mathrm{EG}_{\mathrm{sos}}$ could be explained by that of spring $\mathrm{EG}_{\mathrm{tem}}$, the trend in spring $\mathrm{EG}_{\text {tem }}$ failed to explain the $\mathrm{EG}_{\mathrm{sos}}$ trend (Supplementary Fig. 10a, b). Further analyses suggested that the EGsos trend was also related to elevational gradient changes in the temperature 
a

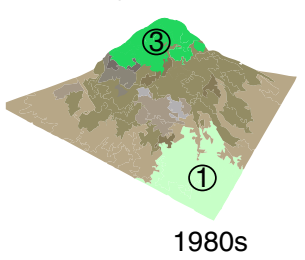

C Category $2 \mathrm{~A}$

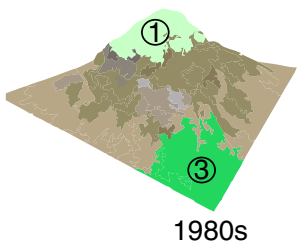

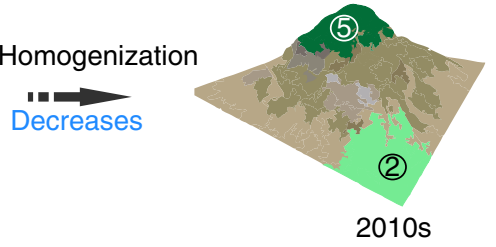

b Category 1B

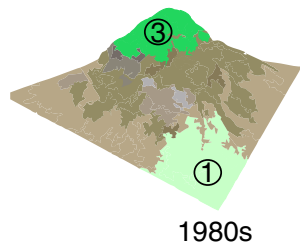

d Category $2 \mathrm{~B}$

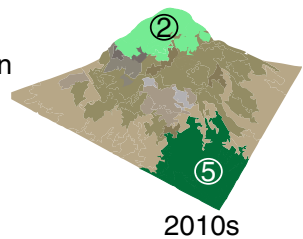

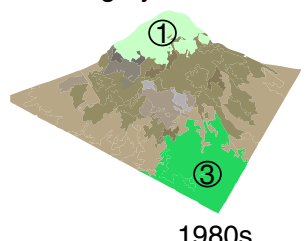

1980s

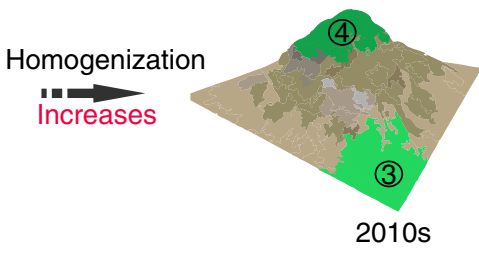

2010s
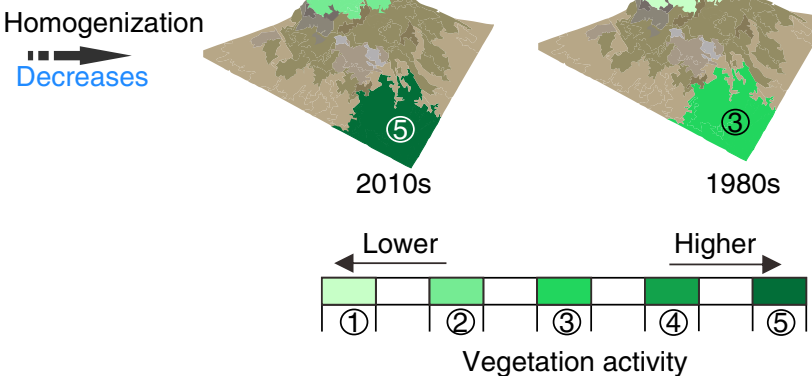

Fig. 3 A diagram of changes in vegetation homogenization along elevational gradients. The vegetation activity here is showcased with the example of the

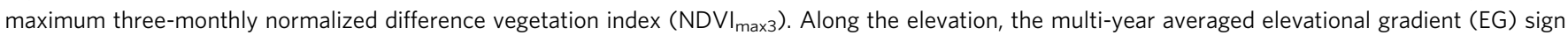
can be either (1) increasing vegetation activity (positive $E_{\text {ndvimax }}$ ) or (2) decreasing vegetation activity (negative $E G_{\text {ndvimax }}$ ). Over time, the $E G$ sign can either $(A)$ amplified or $(B)$ reduced. The combined changes along the elevation and over time for EG dynamics are illuminated in Fig. 3. Here (1A, a) and $(2 A, \mathbf{c})$ indicate decreased elevational vegetation homogenization; while $(1 B, \mathbf{b})$ and $(2 B$, d) imply increased vegetation homogenization

sensitivity (St) of spring phenology (Supplementary Fig. 10c, see Methods). Based on the signs of the $\mathrm{EG}_{\mathrm{SO}}$ trend, the spring $\mathrm{EG}_{\text {tem }}$ trend, and the elevational gradient changes in $\mathrm{St}\left(\mathrm{EG}_{\mathrm{St}}\right)$ of spring phenology, we also grouped all grids into another four categories according to the dominance of $\mathrm{EG}_{\text {tem }}$ and $\mathrm{EG}_{\mathrm{St}}$ in controlling the $\mathrm{EG}_{\mathrm{SOS}}$ trend (see Methods). We found that for about $31 \%$ of the Northern Hemisphere $(\mathrm{NH})$ land area, the trend in $\mathrm{EG}_{\mathrm{SO}}$ was controlled by $\mathrm{EG}_{\mathrm{St}}$, and also for about $31 \%$ of the $\mathrm{NH}$, it was controlled by both $\mathrm{EG}_{\mathrm{St}}$ and $\mathrm{EG}_{\mathrm{tem}}$ (Supplementary Fig. 10d). On the other hand, in only about $20 \%$ of the area where the trend in $\mathrm{EG}_{\mathrm{SO}}$ was controlled by $\mathrm{EG}_{\text {tem }}$ (Supplementary Fig. 10d). Hence, the spatial pattern of EG $E_{\text {Sos }}$ trends was more dominated by changes in the temperature sensitivity of spring phenology instead of by changes in spring temperature. This important role of spring phenology sensitivity to temperature in shaping the spatial pattern of spring phenology was previously reported $^{33,34}$.

\section{Discussion}

We examined the spatio-temporal patterns of the elevational gradients of three vegetation activity indices representing vegetation greenness and phenology since 1982, and found a clear geographical pattern in the EG of vegetation greenness and spring phenology, but not in the EG of autumn phenology. Elevational temperature lapse was the dominant factor determining the elevational changes of spring phenology. Temperature was also important in shaping the EG of vegetation greenness; however, its significance and even the regulating mechanisms for the EG of vegetation greenness in tropical vs. boreal mountains were very different. The lack of explicit geographical pattern for the elevational gradient of autumn phenology and the spatial mismatch between the elevational gradients of autumn temperature and that of autumn phenology suggested that temperature may not be the main controlling factor for the EG of autumn phenology at the global scale. Little is known about the mechanisms controlling autumn phenology, especially when compared to our understanding of spring phenology. Further work on understanding mountainous autumn phenology is thus critically needed. Overall, our findings on the spatial patterns of the EG of vegetation activities suggest that temperature is not the sole dominant factor shaping the vegetation-elevation relationship, and highlights the importance of understanding vegetation activities and their drivers in the spatial context.

More importantly, we also found highly variable temporal changes for the elevational gradients of all vegetation activities (Fig. 4), in contrast to the hypothesized increased vegetation greenness homogenization or vegetation phenology synchronization along the elevational gradient in response to climate change. Furthermore, previous concerns of more homogenized/ synchronized vegetation activities were based on the findings of enhanced warming rate at higher elevations ${ }^{13,35-37}$ and the assumption of the dominant role of temperature in determining vegetation activities ${ }^{5,14,36}$. Nonetheless, Zeng et al. ${ }^{37}$ suggested that warming is not always occurring faster at higher elevations. While vegetation activities can be more sensitive to climate change at higher elevations $s^{3,5,38}$, here we also find that mechanisms governing the spatio-temporal dynamics of the elevational gradients of vegetation greenness and phenology are not globally universal. Elevation-dependent warming did indeed lead to a reduction in the difference of spring phenology timing across the elevation gradient in some regions like the Alps ${ }^{39}$, yet temperature is not the sole element regulating the vegetation-elevation relationship ${ }^{40,41}$. Precipitation and human activities, for instance, have both played important roles in determining the elevational gradients of vegetation activities and their changes ${ }^{40,42-45}$, with various contributions in different areas. Furthermore, these multiple factors that control the vegetation-elevation relationship, as well as their recent dynamics, are highly heterogeneous across the global land surface. Such heterogeneities probably underpin the highly variable responses of the vegetation-elevation relationship to recent climate change. These variable vegetation- 
a Spatial patterns of four different $\mathrm{EG}_{\text {ndvimax }}$ categories

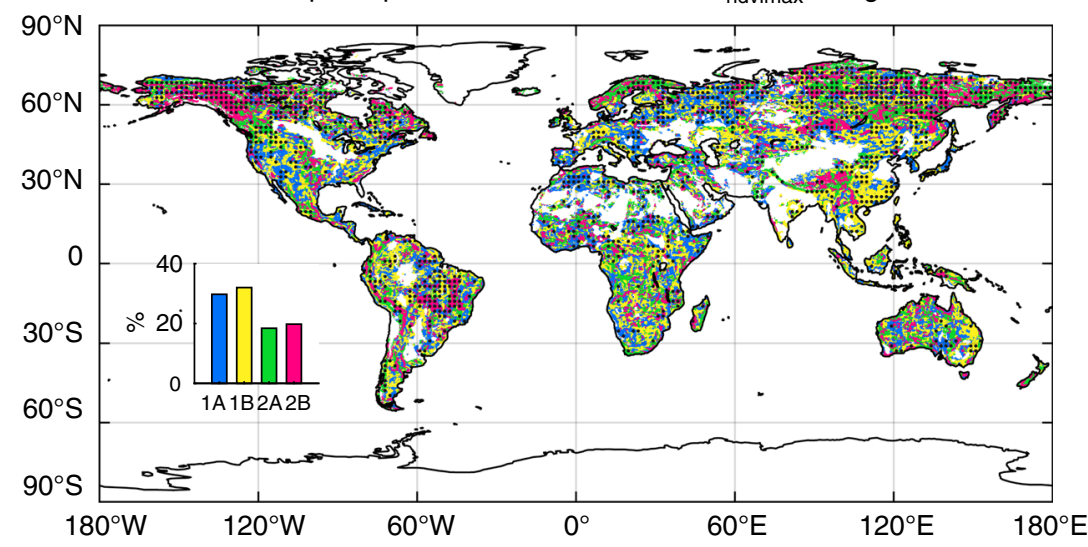

b

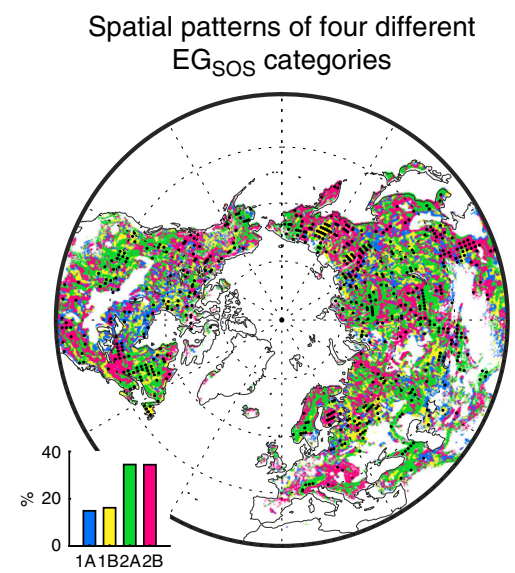

C Spatial patterns of four different

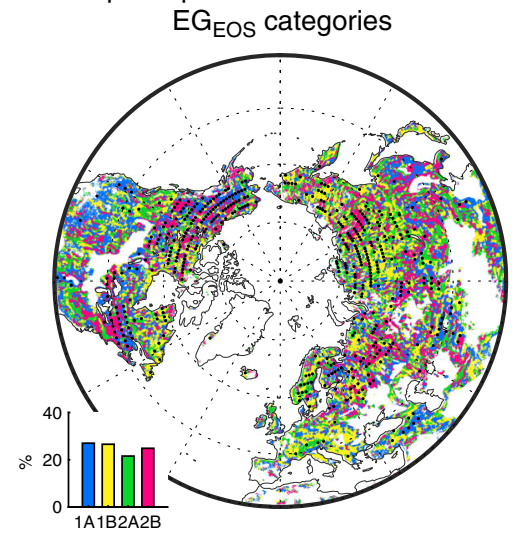

Fig. 4 Spatial patterns of different temporal trends of the elevational gradient (EG) of vegetation activities. a The spatial pattern of different categories of the temporal trends in $\mathrm{EG}_{\text {ndvimax }}$ during 1982-2015. b The spatial pattern of different categories of the temporal trends in $\mathrm{EG}_{\mathrm{SOS}}$ during $1982-2011$ over the Northern Hemisphere (north of $30^{\circ} \mathrm{N}$ ). c The spatial pattern of different categories of the temporal trends in EG EOs during 1982-2011 over the Northern Hemisphere (north of $30^{\circ} \mathrm{N}$ ). Category colors in this figure correspond to that shown in Fig. 3. Regions marked with dots have statistically significant $\left(p<0.05\right.$ with the $F$-test) $E G$ values. The area fraction of each of the four different categories in the temporal trends of $E_{\text {ndvimax }} / E_{\text {sos }} / E_{E_{E O S}}$ is shown in the inset at bottom-left for each panel

elevation responses under climate change need to be further investigated for better understanding and improved prediction of future vegetation activities under different climate scenarios.

Our results are subject to a few caveats. First, we used climate data from the Worldclim dataset, which was interpolated from meteorological station records. Considerable errors in deriving the gridded climate values in the dataset, particular in high latitude areas, may arise from the sparse distribution of meteorological stations. For example, the uniform pattern of $\mathrm{EG}_{\text {pre }}$ and $\mathrm{EG}_{\text {tem }}$ in high latitudes may be partly caused by the fact that climate in the surrounding grids was likely interpolated from the same station data (Fig. 2a, b). More meteorological stations are thus needed in data-sparse areas, especially at higher latitudes.

Second, the GIMMS $\mathrm{NDVI}_{3 \mathrm{~g}}$ dataset used in this study is at a spatial resolution of $8 \mathrm{~km} \times 8 \mathrm{~km}$, which can be rough for mountainous areas. However, this GIMMS NDVI 3 dataset is still likely the best one we can currently use for a global-scale analysis. For example, although the MODIS NDVI or EVI datasets has a higher spatial resolution, they cover a relatively short time period only since 2000. Future development of higher-resolution satellite datasets may further improve the robustness of such global-scale analyses of vegetation activity dynamics. To test the robustness of our satellite-based findings on the spatio-temporal EG trends of vegetation phenology, we perform the same analysis with a pan European phenological database PEP725, the largest ground-based phenological monitoring network. We find that the spatial pattern of ground-based $\mathrm{EG}_{\mathrm{SO}}$ is similar to that of satellite-based, i.e., later leaf unfolded date with increasing elevation (Fig. 5a, b); and the area fraction of each of the four different spatio-temporal EG trend categories for ground-based $\mathrm{EG}_{\mathrm{SO}}$ is also consistent with that of satellite-based $\mathrm{EG}_{\mathrm{SOS}}$ (Fig. 5c, d). This again confirms the robustness of our finding based on large-scale satellite data analysis. However, for EOS, most regions show negative correlations between leaf coloration date and elevation (sooner start of leaf coloring at higher elevations) in station-based $\mathrm{EG}_{\mathrm{EOS}}$, a pattern in weak agreement with that from satellite data (Fig. 6a, b). Such discrepancy between satellite- and ground-based $\mathrm{EG}_{\mathrm{EO}}$ spatial patterns in central Europe may partly arise from the sparse distribution of ground-based phenological stations, where only about $14.4 \pm 5.8$ sites have records for leaf unfold date and $12.1 \pm 4.4$ sites for leaf coloration for one $9 \times 9$ moving window. Furthermore, EOS from ground-based measurements is defined as the date with $50 \%$ leaf coloration, which may not be the same as satellite-based EOS derived from different algorithms detecting the abrupt change of NDVI. Nevertheless, the ground-based result still supports our major finding of no clear sign for increased elevational autumn phenology synchronization (Fig. 6c, d).

While our results do not support a prevalent trend of the elevational homogenization/synchronization of vegetation activities, such trends of recently increased homogenization/synchronization 
a

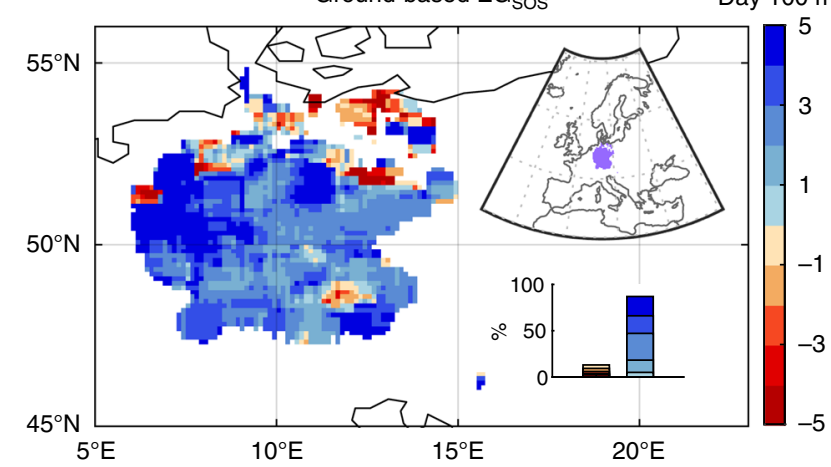

C

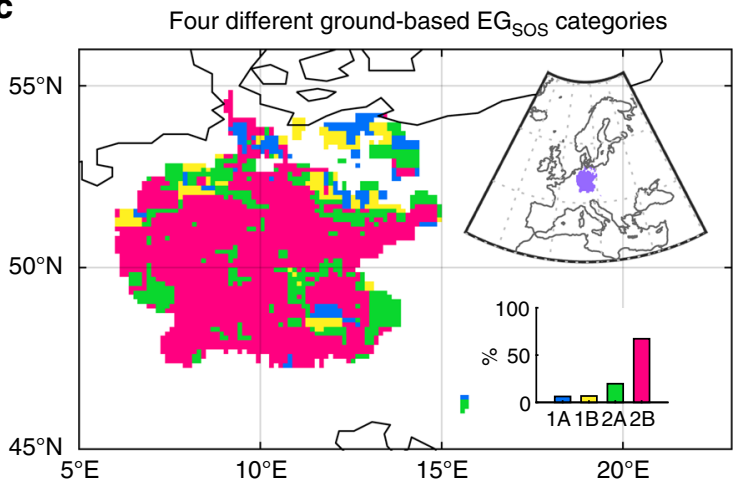

b

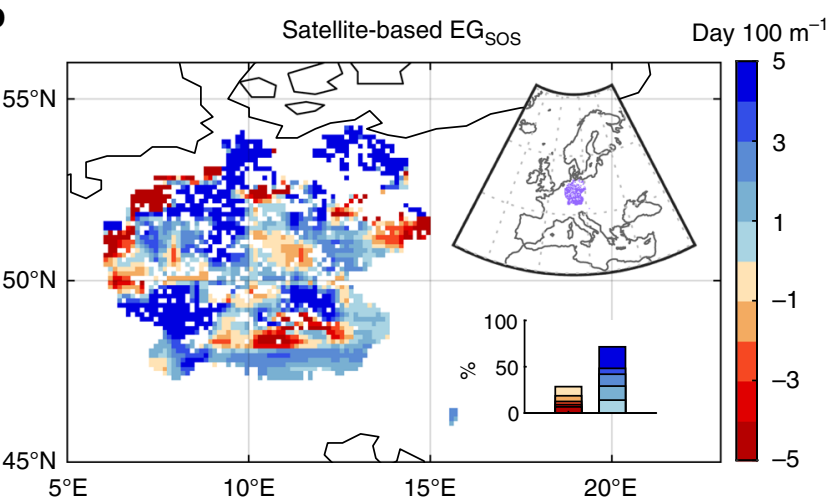

d

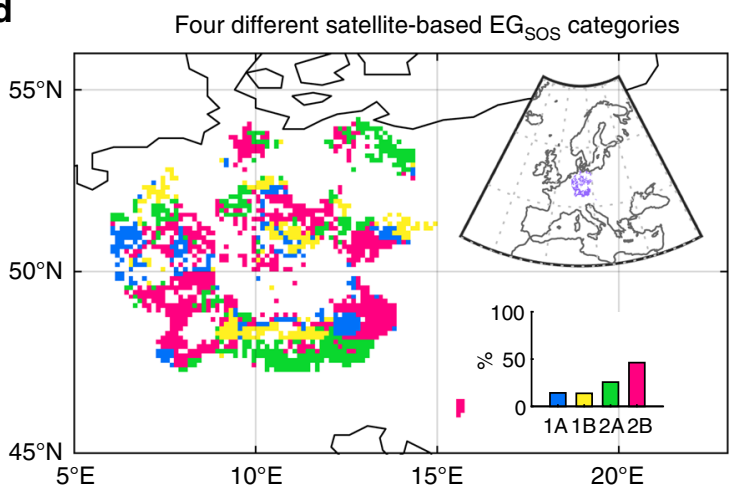

Fig. 5 Spatial patterns of the elevational gradient of SOS ( $\mathrm{EG}_{\mathrm{SOS}}$ ) and their temporal trends. a The spatial pattern of ground-based $\mathrm{EG}_{\mathrm{SOS}}$ from 1982 to 2011. b The spatial pattern of satellite-based $\mathrm{EG}_{\mathrm{sos}}$ from 1982 to 2011. Frequency distribution of the $\mathrm{EG}_{\mathrm{SOS}}$ values is shown in the inset at the bottom-right for each panel. c The spatial pattern of different categories of the temporal trends in ground-based EGsos during 1982-2011. d The spatial pattern of different categories of the temporal trends in satellite-based EG $_{\mathrm{SOS}}$ during 1982-2011. The area fraction of each of the four different categories in the temporal trends of $\mathrm{EG}_{\mathrm{SO}}$ is shown in the inset at bottom-right for each panel. The location of the regions with European phenology stations is shown in the inset at top-right for each panel

do appear in some regions (Fig. 4). Vegetation homogenization may have critical implications for landscape-scale diversity and ecosystem function ${ }^{46}$. For example, the increased vegetation phenological synchronization may reshuffle species composition and reduce species functional diversity ${ }^{47}$. Mountain areas harbor the most diverse terrestrial ecosystems and provide key ecosystem services, such as aesthetic appreciation, carbon storage, water conservation, and so on ${ }^{48,49}$. Increased vegetation homogenization and reduced species functional diversity along elevational gradients may impair the capacity of mountain ecosystems in providing these key services. Hence, for regions that do experience elevational vegetation homogenization, there is a great need to adopt appropriate policy tools to mitigate the adverse ecosystem impacts of such vegetation homogenization. These policy tools should be based on findings of region specific mechanisms driving the trend of vegetation homogenization.

Nonetheless, for most regions, we did not find apparent homogenization/synchronization trends in the EG of vegetation activities, nor do we have a clear answer on what drives them. More importantly, where a general rule governing the vegetation EG dynamics is lacking, even for regions where the vegetation EG trend was found to be statistically correlated with one or another environmental factor during the study period of 1982-2015, it remains highly uncertain how the vegetation EG will change in the future. This uncertainty imposes great challenges in predicting future landscape vegetation homogenization or phenology synchronization. It subsequently also casts uncertainty in best options for managing ecosystems to mitigate possible adverse impacts of climate change on mountainous biological diversity and ecosystem services.

\section{Methods}

Satellite-sensed vegetation index data. Normalized Difference Vegetation Index (NDVI) data is widely used as a proxy of vegetation greenness and photosynthetic activity ${ }^{50,51}$. Here we used the third generation Global Inventory Monitoring and Modeling Studies (GIMMS) group NDVI dataset ${ }^{52}$ (referred as $\mathrm{NDVI}_{3 \mathrm{~g}}$ ). The dataset has a 15-day temporal frequency from 1982 to 2015 with a spatial resolution of $8 \mathrm{~km}$. We removed cropland-dominated grids from the analysis for their intense human management. Specifically, grids with more than $80 \%$ coverage by croplands according to the MODIS MCD12C1 land cover classification ${ }^{53}$ were excluded. Note that this study excluded regions with bare soil/sparse vegetation where multi-year average NDVI is below 0.1 .

Climate dataset. Monthly average temperature and precipitation data used in this study was acquired from the Worldclim version 2 dataset ${ }^{23}$. The Worldclim dataset was generated by interpolating the average values of climatic records from 9000-60000 weather stations using thin-plate splines for the period 1970-2000, with a high spatial resolution of about $1 \mathrm{~km} \times 1 \mathrm{~km}$. We also used the reanalysis dataset ERA Interim dataset ${ }^{24}$ from the European Centre for Medium-Range Weather Forecasts (ECMWF), which provides monthly air temperature and precipitation data at a spatial resolution of $12 \mathrm{~km}$ for the period 1979-2018.

Human activity dataset. The global datasets of population density and night light can represent the strength of human activities. Here the population density data were obtained from the Gridded Population of the World version 4 data (GPW v4) from the Socioeconomic Data and Applications Center at Columbia University. Population density for the years of 2000, 2005, 2010, and 2015 from GPW v4 was estimated at a spatial resolution of $1 \mathrm{~km} \times 1 \mathrm{~km}$, using an annualized growth rate extrapolation method based on the 2010 round of Population and Housing Censuses $^{54}$. Night light data with a spatial resolution of 30 arc-seconds (approximately $1 \mathrm{~km}$ ) for the period $1992-2013$, covering regions from $65^{\circ} \mathrm{S}$ to $75^{\circ} \mathrm{N}$, were 
a

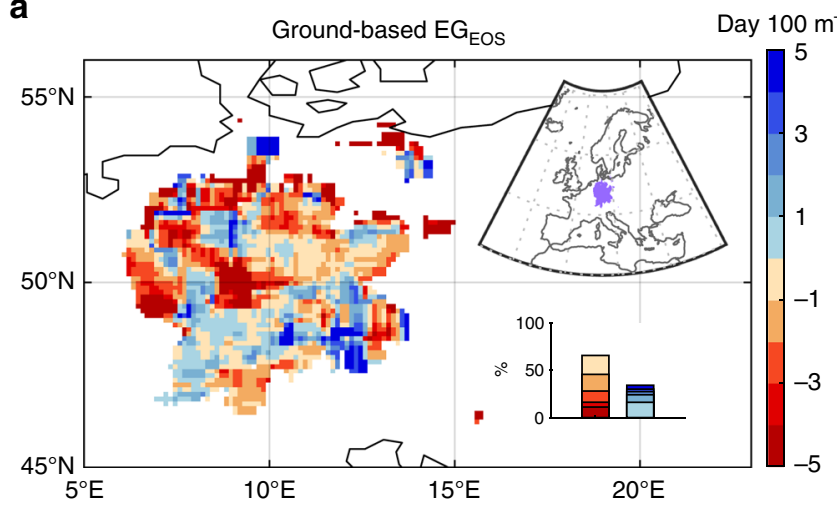

C

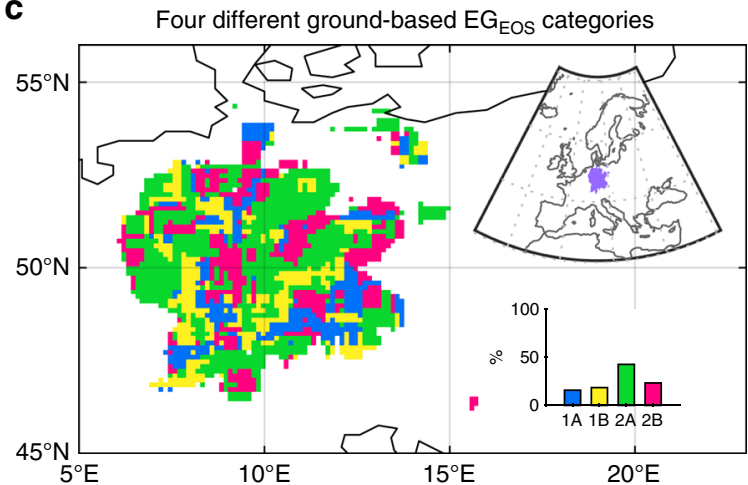

b

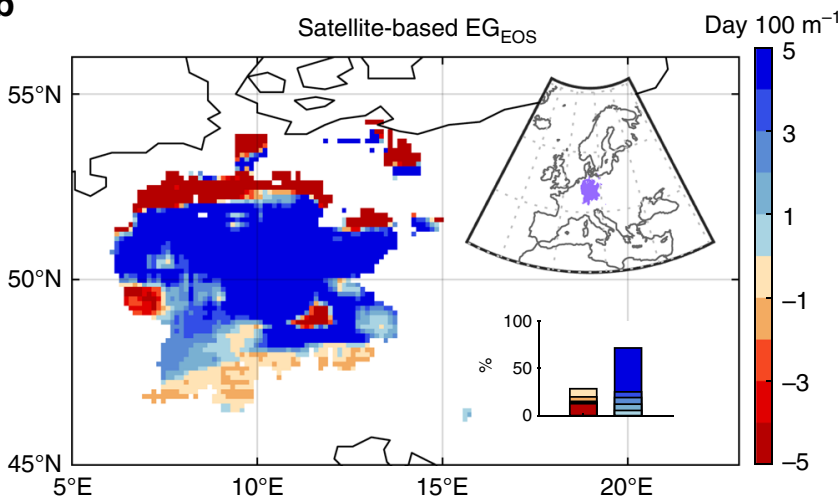

d

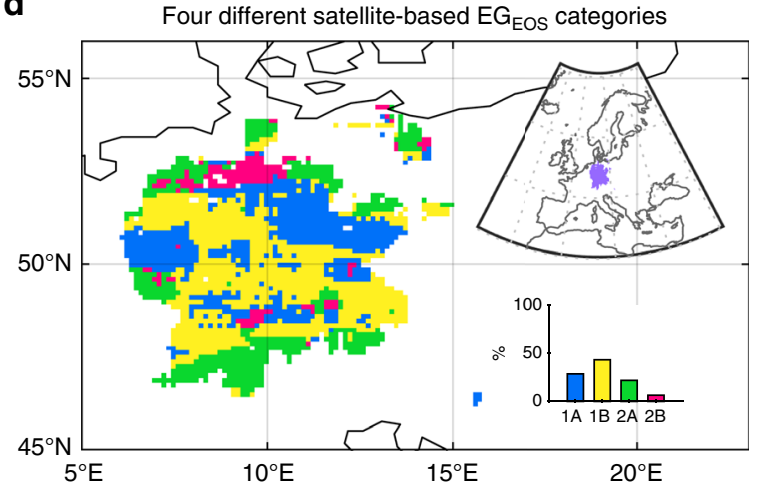

Fig. 6 Spatial patterns of the elevational gradient of EOS ( $E G_{E O S}$ ) and their temporal trends. a The spatial pattern of ground-based $E G_{E O S}$ from 1982 to 2011. b The spatial pattern of satellite-based $\mathrm{EG}_{\mathrm{EOS}}$ from 1982 to 2011 . Frequency distribution of the $\mathrm{EG}_{\mathrm{EO}}$ values is shown in the inset at the bottom-right for each panel. c The spatial pattern of different categories of the temporal trends in ground-based EG EOS during 1982-2011. d The spatial pattern of different categories of the temporal trends in satellite-based $\mathrm{EG}_{\mathrm{EOS}}$ during 1982-2011. The area fraction of each of the four different categories in the temporal trends of $E G_{E O S}$ is shown in the inset at bottom-right for each panel. The location of the regions with European phenology stations is shown in the inset at top-right for each panel

downloaded from the Defense Meteorological Satellite Program-Operational Linescan System (DMSP-OLS) night light dataset ${ }^{55}$, which was derived from the National Oceanic and Atmospheric Administration (NOAA) National Geographic Data Center (NGDC).

Ground-based phenology observation dataset. The ground-based phenology observation data are obtained across Central Europe from the Pan European Phenological database (PEP725). We seleted the records of the first leaf unfolding date and 50\% leaf coloration date from 2256 sites and focused on the sites with continuous records for 1982-2011.

Vegetation activity indicators. The maximum three-monthly $\mathrm{NDVI}_{\max 3}$ was calculated following the below steps: (i) calculating the mean monthly NDVI value for the period 1982-2015, and (ii) sorting the twelve average-monthly NDVI values to obtain the first three maximum values.

We also derived two phenological indices from the GIMMS NDVI ${ }_{3 \mathrm{~g}}$ dataset, i.e. the SOS and the EOS. The SOS date was calculated as the average SOS date estimated by the below four methods: HANTS (harmonic analysis of time series), polyfit, timesat and spline $e^{56-58}$. The EOS date was obtained from the averaged EOS date estimated by the following four methods: HANTS, double logistic, piecewise logistic, and polyfit ${ }^{15,57,59-61}$.

The calculation of elevation gradients. Before analyses, all datasets were resampled into a unified spatial resolution of $8 \mathrm{~km}$ (the same as the NDVI data). The elevation gradient of $\mathrm{NDVI}_{\max 3}\left(\mathrm{EG}_{\text {ndvimax }}\right)$ was calculated as the linear regression slope of the 34-year-averaged NDVI $\max _{3}$ against elevation for each $9 \times 9$ moving window. Digital Elevation Model (DEM) data ${ }^{62}$ was obtained from the Shuttle Radar Topographic Mission (SRTM) with a spatial resolution of $30 \mathrm{~m}$. Similarly, the elevation gradient of $\mathrm{SOS} / \mathrm{EOS}\left(\mathrm{EG}_{\mathrm{SOS}} / \mathrm{EG}_{\mathrm{EOS}}\right)$ was calculated as the linear regression slope of the multi-year-averaged of SOS/EOS against elevation within each $9 \times 9$ moving window. The elevation gradients of temperature $\left(\mathrm{EG}_{\mathrm{tem}}\right)$, total precipitation $\left(\mathrm{EG}_{\mathrm{pre}}\right)$, population density $\left(\mathrm{EG}_{\mathrm{pd}}\right)$, and night light index $\left(\mathrm{EG}_{\mathrm{NLI}}\right)$ were also calculated using the same methods. A positive elevation gradient indicates that the value of focused index is higher at higher elevations, while a negative one suggests that the value is higher at lower elevations. The statistical significance of the elevation gradient was determined by $95 \%$ confidence intervals. Note that only $9 \times 9$ windows with more than 40 grid cells of valid vegetation index values and more than $50 \mathrm{~m}$ in elevation difference were chosen for the regression analysis. Similar analyses were also performed using $5 \times 5,7 \times 7,11 \times 11$ or $13 \times 13$ moving windows to test the robustness of the results. Note that only $9 \times 9$ windows with more than 40 grid cells of valid vegetation index values and more than 50 meters in elevation difference were chosen for the regression analysis. Based on the Pan European Phenological database (PEP725), We calculate the elevation gradient of SOS (EOS) as the linear regression slope of leaf unfolded date (leaf coloration date) for each $9 \times 9$ moving window with more than five stations the same way as we do for satellite-based analyses.

Driving factors of temporal trends in EG. To investigate possible effects of climate change and human activities on the temporal trends in vegetation activity EG, for each pixel we obtained the linear trends of EG in vegetation activity, climate, and night light index during 1982-2015 based on least-squares regressions. Note the data of night light index is available for 1982-2013; and because the number of available population density data for each grid during the study period is only 4 , we therefore calculated the elevational gradient of the population density difference between 2015 and $2000\left(\mathrm{EG}_{\mathrm{pd} d \mathrm{~d}}\right)$, rather than estimating the trend in $\mathrm{EG}_{\mathrm{pd}}$

Note EG of vegetation phenology can also be influenced by phenology temperature sensitivity ${ }^{34}$. We therefore also calculated the elevational gradient of the temperature sensitivity of vegetation phenology. The elevational gradient of the temperature sensitivity of SOS was calculated as the following steps. (i) For each pixel, the preseason was determined as the period before SOS for which the absolute value of the correlation coefficient between SOS and air temperature was highest ${ }^{63}$. Note that since the relationship between SOS and temperature is usually regarded as negative, respectively, we thus exclude those positive correlation coefficients for SOS. (ii) For each $9 \times 9$ moving spatial window, we used an identical preseason length, which is the median values of preseason length of each grid. (iii) The temperature sensitivity of SOS was calculated using a linear regression for the period 1982-2011 with temperature as the dependent variable and SOS as the independent variable. (iv) The elevational gradient of temperature sensitivity of SOS was estimated for each $9 \times 9$ moving window. To examine the dominant factor driving the temporal change of $\mathrm{EG}_{\mathrm{SOS}}$, we classified all grid into another four 
categories (categories a-d in Supplementary Table 1) based on the sign of $\mathrm{EG}_{\mathrm{SO}}$ trends, spring $\mathrm{EG}_{\text {tem }}$ trends, and elevation gradients of temperature sensitivity of SOS: (a) the $\mathrm{EG}_{\mathrm{SOS}}$ trend is co-determined by both $\mathrm{EG}_{\text {tem }}$ and the temperature sensitivity of SOS, (b) the $\mathrm{EG}_{\mathrm{SOS}}$ trend is primarily driven by the temperature sensitivity of SOS, (c) the $\mathrm{EG}_{\mathrm{SO}}$ trend is primarily driven by spring $\mathrm{EG}_{\mathrm{tem}}$, (d) the $\mathrm{EG}_{\mathrm{SOS}}$ trend is possibly driven by other factors.

Reporting summary. Further information on research design is available in the Nature Research Reporting Summary linked to this article.

\section{Data availability}

The AVHRR GIMMS NDVI ${ }_{3 \mathrm{~g}}$ datasets are available at https:/ecocast.arc.nasa.gov/data/ pub/gimms/3g.vl/. The Worldclim version 2 datasets can be accessed through website http://worldclim.org/version2. The ERA Interim datasets can be downloaded from website https://www.ecmwfint/en/forecasts/datasets/reanalysis-datasets/erainterim. The Gridded Population of the World version 4 datasets (GPW v4) are available at http://sedac.ciesin.columbia.edu/data/collection/gpw-v4. The Night light data can be downloaded from https://www.ngdc.noaa.gov/eog/dmsp/downloadV4composites.html. The PEP725 database is available at http://www.pep725.eu/. All the relevant data from this study are also available from the corresponding author upon request.

\section{Code availability}

All computer codes for the analysis of the data are available from the corresponding author on reasonable request.

Received: 2 January 2019 Accepted: 16 June 2019

Published online: 05 July 2019

\section{References}

1. Von Humboldt, A. et al. Cosmos: a sketch of a physical description of the universe. (H.G. Bohn. Press, London,1859).

2. Körner, C. The use of 'altitude' in ecological research. Trends Ecol. Evol. 22, 569-574 (2007).

3. Piao, S. et al. Altitude and temperature dependence of change in the spring vegetation green-up date from 1982 to 2006 in the Qinghai-Xizang Plateau. Agric. For. Meteorol. 151, 1599-1608 (2011).

4. Guyon, D. et al. Monitoring elevation variations in leaf phenology of deciduous broadleaf forests from SPOT/VEGETATION time-series. Remote Sens. Environ. 115, 615-627 (2011)

5. Li, H. et al. Pattern of NDVI-based vegetation greening along an altitudinal gradient in the eastern Himalayas and its response to global warming. Environ. Monit. Assess. 188, https://doi.org/10.1007/s10661-016-5196-4 (2016).

6. Richardson, A. D. et al. Climate change, phenology, and phenological control of vegetation feedbacks to the climate system. Agric. For. Meteorol. 169, 156-173 (2013).

7. Tao, J. et al. Elevation-dependent effects of climate change on vegetation greenness in the high mountains of southwest China during 1982-2013. Int. J. Climatol. 2038, 2029-2038 (2018).

8. Kitayama, K. An altitudinal transect study of the vegetation on Mount Kinabalu, Borneo. Vegetatio 102, 149-171 (1992).

9. Krishnaswamy, J. et al. Consistent response of vegetation dynamics to recent climate change in tropical mountain regions. Glob. Chang. Biol. 20, 203-215 (2014).

10. Lenoir, J. et al. A significant upward shift in plant species optimum elevation during the 20th century. Science 320, 1768-1771 (2008).

11. Bertrand, R. et al. Changes in plant community composition lag behind climate warming in lowland forests. Nauture 479, 517-520 (2011).

12. Pearson, R. G. et al. Shifts in Arctic vegetation and associated feedbacks under climate change. Nat. Clim. Chang 3, 673-677 (2013).

13. Pepin, N. et al. Elevation-dependent warming in mountain regions of the world. Nat. Clim. Chang 5, 424-430 (2015).

14. Wang, X. et al. Spring temperature change and its implication in the change of vegetation growth in North America from 1982 to 2006. Proc. Natl Acad. Sci. USA 108, 1240-1245 (2011).

15. Zhang, X. et al. Monitoring vegetation phenology using MODIS. Remote Sens. Environ. 84, 471-475 (2003).

16. Alcaraz-Segura, D. et al. Debating the greening vs. browning of the North American boreal forest: differences between satellite datasets. Glob. Chang. Biol. 16, 760-770 (2010).

17. Menzel, A. et al. European phenological response to climate change matches the warming pattern. Glob. Chang. Biol. 12, 1969-1976 (2006).

18. Corlett, R. T. Impacts of warming on tropical lowland rainforests. Trends Ecol. Evol. 26, 606-613 (2011)
19. Doughty, C. E. \& Goulden, M. L. Are tropical forests near a high temperature threshold? J. Geophys. Res. Biogeosci. 114, https://doi.org/10.1029/ 2007JG000632 (2009).

20. Deng, S. F. et al. Vegetation cover variation in the Qilian Mountains and its response to climate change in 2000-2011. J. Mt. Sci. 10, 1050-1062 (2013).

21. Kharuk, V. I. et al. Tree vegetation of the forest-tundra ecotone in the Western Sayan Mountains and climatic trends. Russ. J. Ecol. 39, 8-13 (2008).

22. Bradshaw, R. \& Hannon, G. Climatic change, human influence and disturbance regime in the control of vegetation dynamics within fiby forest, Sweden. J. Ecol. 80, 625-632 (1992).

23. Fick, S. E. \& Hijmans, R. J. WorldClim 2: new 1-km spatial resolution climate surfaces for global land areas. Int. J. Climatol. 37, 4302-4315 (2017).

24. Dee, D. P. et al. The ERA-Interim reanalysis: configuration and performance of the data assimilation system. Q. J. R. Meteorol. Soc. 137, 553-597 (2011).

25. Günter, S. et al. Tree phenology in montane forests of southern Ecuador can be explained by precipitation, radiation and photoperiodic control. J. Trop. Ecol. 24, 247-258 (2008).

26. Fu, Y. H. et al. Declining global warming effects on the phenology of spring leaf unfolding. Nature 526, 104-107 (2015).

27. Liu, Q. et al. Delayed autumn phenology in the Northern Hemisphere is related to change in both climate and spring phenology. Glob. Chang. Biol. 22, 3702-3711 (2016).

28. Gan, S. \& Amasino, R. M. Making sense of senescence. Plant Physiol. 113 313-319 (1997)

29. Estiarte, M. \& Peñuelas, J. Alteration of the phenology of leaf senescence and fall in winter deciduous species by climate change: effects on nutrient proficiency. Glob. Chang. Biol. 21, 1005-1017 (2015).

30. Liu, Q. et al. Temperature, precipitation, and insolation effects on autumn vegetation phenology in temperate China. Glob. Chang. Biol. 22, 644-655 (2016).

31. Peng, S.-S. et al. Afforestation in China cools local land surface temperature. Proc. Natl Acad. Sci. USA 111, 2915-2919 (2014).

32. Li, Y. et al. Divergent hydrological response to large-scale afforestation and vegetation greening in China. Sci. Adv. 4, https://doi.org/10.1126/sciadv. aar4182 (2018).

33. Shen, M. et al. Earlier-season vegetation has greater temperature sensitivity of spring phenology in northern hemisphere. PLoS One 9, https://doi.org/ 10.1371/journal.pone.0088178 (2014).

34. Shen, M. et al. Temperature sensitivity as an explanation of the latitudinal pattern of green-up date trend in Northern Hemisphere vegetation during 1982-2008. Int. J. Climatol. 35, 3707-3712 (2015).

35. Yan, L. \& Liu, X. Has climatic warming over the Tibetan Plateau paused or continued in recent years?. J. Earth Ocean Atmos. Sci. 1, 13-28 (2014).

36. Piao, S. et al. Growing season extension and its impact on terrestrial carbon cycle in the Northern Hemisphere over the past 2 decades. Glob. Biogeochem. Cycles 21, 1-11 (2007).

37. Zeng, Z. et al. Regional air pollution brightening reverses the greenhouse gases induced warming-elevation relationship. Geophys. Res. Lett. 42, 4563-4572 (2015).

38. Tao, J. et al. Elevation-dependent relationships between climate change and grassland vegetation variation across the Qinghai-Xizang Plateau. Int. J. Climatol. 35, 1638-1647 (2015).

39. Vitasse, Y. et al. Global warming leads to more uniform spring phenology across elevations. Proc. Natl Acad. Sci. USA 115, 1004-1008 (2017).

40. Shen, M. et al. Precipitation impacts on vegetation spring phenology on the Tibetan Plateau. Glob. Chang. Biol. 21, 3647-3656 (2015).

41. Schultz, P. A. \& Halpert, M. S. Global correlation of temperature, NDVI and precipitation. Adv. Sp. Res 13, 277-280 (1993).

42. Schultz, P. A. \& Halpert, M. S. Global analysis of the relationships among a vegetation index, precipitation and land surface temperature. Int. J. Remote Sens. 16, 2755-2777 (1995).

43. Kawabata, A. et al. Global monitoring of interannual changes in vegetation activities using NDVI and its relationships to temperature and precipitation. Int. J. Remote Sens. 22, 1377-1382 (2001).

44. Zhu, Z. et al. Greening of the Earth and its drivers. Nat. Clim. Chang 6, 791-795 (2016)

45. Piao, S. et al. Detection and attribution of vegetation greening trend in China over the last 30 years. Glob. Chang. Biol. 21, 1601-1609 (2015).

46. Chuine, I. \& Beaubien, E. Phenology is a major determinant of tree species range. Ecol. Lett. 4, 500-510 (2001)

47. Inouye, D. W. et al. Climate change is affecting altitudinal migrants and hibernating species. Proc. Natl Acad. Sci. USA 97, 1630-1633 (2000)

48. Messerli, B. \& Ives, J. D. Mountains of the world: a global priority (Parthenon Publishing Group, New York, 1997).

49. Viviroli, D. et al. Mountains of the world, water towers for humanity: Typology, mapping, and global significance. Water Resour. Res. 43, 1-13 (2007).

50. Tucker, C. J. et al. Relationship between atmospheric $\mathrm{CO} 2$ variations and a satellite-derived vegetation index. Nature 319, 195-199 (1986). 
51. Pettorelli, N. et al. Using the satellite-derived NDVI to assess ecological responses to environmental change. Trends Ecol. Evol. 20, 503-510 (2005).

52. Tucker, C. J. et al. An extended AVHRR 8-km NDVI dataset compatible with MODIS and SPOT vegetation NDVI data. Int. J. Remote Sens. 26, 4485-4498 (2005).

53. Friedl, M. A. et al. MODIS Collection 5 global land cover: algorithm refinements and characterization of new datasets. Remote Sens. Environ. 114, 168-182 (2010).

54. Center for International Earth Science Information Network-CIESINColumbia University. Gridded Population of the World, Version 4 (GPWv4): Population Density. Palisades, NY: NASA Socioeconomic Data and Applications Center (SEDAC), https://doi.org/10.7927/H4NP22DQ (2016).

55. Elvidge, C. D. et al. Mapping city lights with nighttime data from the DMSP operational linescan system. Photogramm. Eng. Remote Sens. 63, 727-734 (1997).

56. Cong, N. et al. Changes in satellite-derived spring vegetation green-up date and its linkage to climate in China from 1982 to 2010: a multimethod analysis. Glob. Chang. Biol. 19, 881-891 (2013).

57. Piao, S. et al. Variations in satellite-derived phenology in China's temperate vegetation. Glob. Chang. Biol. 12, 672-685 (2006).

58. White, M. A. et al. Intercomparison, interpretation, and assessment of spring phenology in North America estimated from remote sensing for 1982-2006. Glob. Chang. Biol. 15, 2335-2359 (2009).

59. Jakubauskas, M. E. et al. Harmonic analysis of time-series AVHRR NDVI data. Photogramm. Eng. Remote Sens. 67, 461-470 (2001).

60. De Wit, A. J. W. \& Su. B. Deriving phenological indicators from SPOT-VGT data using the HANTS algorithm. In Proc. 2nd international SPOTVEGETATION user conference. 195-201 (EC, Luxembourg, 2005).

61. Pinty, B. et al. Retrieving surface parameters for climate models from moderate resolution imaging spectroradiometer (MODIS)-multiangle imaging spectroradiometer (MISR) albedo products. J. Geophys. Res. Atmos. 112, 1-23 (2007).

62. Van Zyl, J. J. The shuttle radar topography mission (srtm): a breakthrough in remote sensing of topography. Acta Astronaut. 48, 559-565 (2001)

63. Piao, S. et al. Leaf onset in the northern hemisphere triggered by daytime temperature. Nat. Commun. 6, https://doi.org/10.1038/ncomms7911 (2015).

\section{Acknowledgements}

This study was supported by the Strategic Priority Research Program (A) of the Chinese Academy of Sciences (Grant XDA20050101), the National Key R\&D Program of China (2017YFA0604702), the National Natural Science Foundation of China (41861134036,
41530528), the BELSPO STEREO project ECOPROPHET (SR00334), National Youth Top-notch Talent Support Program in China and the 111 Project (B14001). A. C. acknowledges the support from an Oak Ridge National Laboratory subcontract (4000167205)

\section{Author contributions}

S.L.P. designed the research; M.G. performed analysis; M.G. created all the figures; M.G., S.L.P., and A.C. drafted the paper; M.G., S.L.P., A.C., H.Y., Q.L., Y.H.F., and I.A.J. contributed to the interpretation of the results and to the text.

\section{Additional information}

Supplementary Information accompanies this paper at https://doi.org/10.1038/s41467019-11035-w.

Competing interests: The authors declare no competing interests.

Reprints and permission information is available online at http://npg.nature.com/ reprintsandpermissions/

Peer review information: Nature Communications thanks This Rutishauser and other anonymous reviewer(s) for their contribution to the peer review of this work.

Publisher's note: Springer Nature remains neutral with regard to jurisdictional claims in published maps and institutional affiliations.

(c) (1) Open Access This article is licensed under a Creative Commons Attribution 4.0 International License, which permits use, sharing, adaptation, distribution and reproduction in any medium or format, as long as you give appropriate credit to the original author(s) and the source, provide a link to the Creative Commons license, and indicate if changes were made. The images or other third party material in this article are included in the article's Creative Commons license, unless indicated otherwise in a credit line to the material. If material is not included in the article's Creative Commons license and your intended use is not permitted by statutory regulation or exceeds the permitted use, you will need to obtain permission directly from the copyright holder. To view a copy of this license, visit http://creativecommons.org/ licenses/by/4.0/.

() The Author(s) 2019 